\title{
Effect of Long-time Heating for Elements from Flame Retardants in Acrylonitrile Butadiene Styrene and Polycarbonate Resin Disks
}

\author{
Masaki OHata, ${ }^{* \dagger}$ Toshihiro KIDOKORO,* Takamitsu OTAKe, $* *$ Nobuyasu ItoH, ${ }^{* *}$ and \\ Nobuyasu HaNARI** \\ *Inorganic Standards Group, Research Institute for Material and Chemical Measurement (MCM), \\ National Metrology Institute of Japan (NMIJ), National Institute of Advanced Industrial Science \\ and Technology (AIST), 1-1-1 Umezono, Tsukuba, Ibaraki 305-8563, Japan \\ **Organic Analytical Standards Group, Research Institute for Material and Chemical Measurement (MCM), \\ National Metrology Institute of Japan (NMIJ), National Institute of Advanced Industrial Science and \\ Technology (AIST), 1-1-1 Umezono, Tsukuba, Ibaraki 305-8563 Japan
}

\begin{abstract}
The effect of long-time heating for elements from flame retardants (FRs) such as dechlorane plus (DP), tetrabromobisphenol A (TBBPA), triphenyl phosphate (TPhP) and antimony trioxide $\left(\mathrm{Sb}_{2} \mathrm{O}_{3}\right)$ in both acrylonitrile-butadiene-styrene (ABS) and polycarbonate (PC) resin disks was examined in the present study. The heating temperature by a drying oven was $80^{\circ} \mathrm{C}$, which was expected to be a harder environment than that of usual dump site to discard electric and electronic equipment, and the long-time heating was carried out for up to 722 days. As a result, the increases for both ether (C-O-C) and ketone $(\mathrm{C}=\mathrm{O})$ groups and the decrease of $\mathrm{C}=\mathrm{C}$ double bond as well as methylene group $\left(=\mathrm{CH}_{2}\right)$ were found for an $\mathrm{ABS}$ resin disk by fourier transform infrared (FTIR) spectrometry, which was expected to result in an increase of mass of the disk up to ca. $4 \%$ due to oxidation during the long-time heating. The changes in concentrations for bromine $(\mathrm{Br}), \mathrm{chlorine}(\mathrm{Cl})$, phosphorous $(\mathrm{P})$ and $\mathrm{Sb}$, which were originated elements from FRs contained, were also evaluated by energy dispersive $\mathrm{X}$-ray fluorescence (ED-XRF) spectrometry and the decreases in concentrations of $c a$. 5\% in ABS resin disk were observed which could be almost explained by increasing $c a .4 \%$ mass of the disk. On the contrary, the mass and chemical form of a PC resin disk as well as the concentrations of elements contained did not change during the long-time heating. From these results, it could be considered that most of the elements from DP, TBBPA, TPhP and $\mathrm{Sb}_{2} \mathrm{O}_{3}$ contained as FRs in the ABS and PC resin disks examined in the present study were not lost during the long-time heating, even though the color, shape, mass and chemical form of ABS resin disk were changed.
\end{abstract}

Keywords Flame retardant, acrylonitrile-butadiene-styrene, polycarbonate, long-time heating, mass, chemical form, loss of element, oxidation

(Received May 8, 2018; Accepted August 7, 2018; Advance Publication Released Online by J-STAGE August 17, 2018)

\section{Introduction}

Polymers are well known to be widespread used in electrical and electronic equipment and several hazardous substances contained in polymers are regulated in EU RoHS (restriction of the use of hazardous substances in electrical and electronic equipment) directive which became effective since July in 2006. ${ }^{1,2}$ Polymers such as acrylonitrile-butadiene-styrene (ABS) and polycarbonate (PC) are found as major ones in office machinery such as personal computers, printers, and data CDs, and many of them contain flame retardants (FRs) which have been utilized in polymers since the 1960s as one of useful chemical additives for preventing combustion and/or delaying the spread of fire after ignition of materials. ${ }^{3-10}$ Generally, FRs consist of chlorine $(\mathrm{Cl})$, bromine $(\mathrm{Br})$, phosphorus $(\mathrm{P})$, and compounds such as aluminum hydroxide $\left[\mathrm{Al}\left(\mathrm{OH}_{3}\right)\right]$ and antimony trioxide $\left(\mathrm{Sb}_{2} \mathrm{O}_{3}\right) .^{5}$ Particularly, organochlorine,

† To whom correspondence should be addressed.

E-mail: m-oohata@aist.go.jp organobromine and organophosphorus are major ones of organic FRs and are widely used in commercial electric and electronic equipment. ${ }^{4-6}$ Recently, $\mathrm{Sb}_{2} \mathrm{O}_{3}$ has also been widely used to enhance the effect of FRs containing halogens. ${ }^{7}$ On the other hand, commercial products containing FRs may cause environmental contaminations due to the release of FRs. Elevated concentrations of FRs such as polybromodiphenyl ethers (PBDEs) and 1,3-phenylene bis(diphenyl phosphate) have been found in leaves and are believed to affect biosphere from the air and the soil near dump sites for discarded electric and electronic equipment. ${ }^{8-10}$ In addition, commercial products containing FRs are not readily managed throughout the supply chain. Therefore, it is considered that a proper elucidation of the changes in concentrations of FRs in these products is very important. The ageing of additives and polymers such as combinations of FRs and resins as well as antioxidants and rubbers was evaluated in earlier studies; however, it was difficult to catch slight changes in concentrations of additives since their homogeneities in polymers were not evaluated. ${ }^{11,12}$ From this point of view, we prepared plastic disks for both ABS and PC resins containing FRs and homogeneities of FRs were evaluated 
in our previous study. ${ }^{13,14}$ The FRs contained in these plastic disks were dechlorane plus (DP), tetrabromobisphenol A (TBBPA) and triphenyl phosphate (TPhP) which were selected as organochlorine, organobromine and organophosphorus FRs, respectively. The $\mathrm{Sb}_{2} \mathrm{O}_{3}$ was also added to the ABS and $\mathrm{PC}$ resin disks as an inorganic FR. The concentrations of FRs prepared in these plastic disks were $c a .0 .1 \%$ in compliance with the RoHS directive on organobromine FRs and their homogeneities evaluated in compliance with ISO Guide983:2008 ${ }^{15}$ were sufficiently small (maximum inhomogeneity $4.3 \%$ ) to examine the change in concentrations of FRs by ageing or weathering tests. In addition, the plastic disks could be used to evaluate the behavioral differences among FRs in polymers under environmental changes since three or four FRs were contained in the same disks and their concentrations were properly determined. ${ }^{13,14}$ Consequently, the simulated weathering tests, which were independently set as outdoor or indoor exposure in compliance with the ISO 4892-2:2006, ${ }^{16}$ were also performed with respect to the plastic disks. ${ }^{13,14}$ As results, FRs in the plastic disks showed small changes in their concentrations due to the partly decomposition of their chemical forms under the simulated weathering tests which were assumed as scrapyard or office environments for $c a$. 6 months..$^{13,14,17-19}$ On the other hand, another question came out if the plastic disks were exposed to a harder environment such as a higher temperature. It is well known that X-ray fluorescence (XRF) spectrometry is expected to be useful for direct and speedy analysis of hazardous substances in electrical and electronic equipment ${ }^{20-23}$ and also described in the IEC 62321 as a screening method with respect to RoHS directive. ${ }^{24}$ However, the loss of elements in plastics during XRF measurements was also reported for an organometallic compound of $\mathrm{Hg}$ in a plastic certified reference material (CRM) due to its volatility. ${ }^{25}$ In our previous study, we also observed the loss of $\mathrm{Cr}$ from the PP resin disk CRM (NMIJ CRM 8136-a) for long-time measurements by XRF spectrometry. ${ }^{22}$ The temperature observed at the surface of the PP resin disk CRM was $c a .90^{\circ} \mathrm{C}$ after $1 \mathrm{~h}$ measurement by a wavelength dispersive XRF (WD-XRF) spectrometer and the loss of $c a .10 \% \mathrm{Cr}$ was observed during the long-time measurement for $120 \mathrm{~h}$ from the side of the surface irradiated by $\mathrm{X}$-ray. ${ }^{22}$ Since the chemical forms of $\mathrm{Cr}$ for both inorganic and organometallic compounds were mixed in the PP resin disk $\mathrm{CRM}$, the organo one was considered to be lost by the heating from the long-time X-ray irradiation. The effect of long-time heating at $80^{\circ} \mathrm{C}$ was also examined for both PVC and PP resin pellet CRMs to explore the source of the loss of elements in our previous study 22 and the loss of organometallic compound of $\mathrm{Cr}$ was observed. ${ }^{23}$

From these points of view, the long-time heating as a harder environment compared to usual dump site to discard electric and electronic equipment was examined with respect to the elements from FRs contained in plastic disks in the present study. The plastic disks were exposed at $80^{\circ} \mathrm{C}$ in a drying oven for a long-time up to 722 days and the concentrations of elements originated from FRs as well as the change of the masses and chemical forms of the plastic disks were evaluated in the present study.

\section{Experimental}

\section{Samples}

The plastic disks of $\mathrm{ABS}$ or $\mathrm{PC}$ resin containing known concentrations of FRs of DP, TBBPA, TPhP, and $\mathrm{Sb}_{2} \mathrm{O}_{3}$ were used in the present study. The concentrations of DP, TBBPA,
Table 1 Concentrations $\left(\mathrm{mg} \mathrm{kg}^{-1}\right)$ of FRs and related elements in ABS and PC disks

\begin{tabular}{lcc}
\hline & ABS disk & PC disk \\
\hline DP & $449 \pm 6$ & $450 \pm 11$ \\
TBBPA & $909 \pm 26$ & $924 \pm 42$ \\
TPhP & $1011 \pm 27$ & $1023 \pm 31$ \\
$\mathrm{Cl}$ & $329 \pm 3$ & $338 \pm 5$ \\
$\mathrm{Br}$ & $561 \pm 10$ & $568 \pm 10$ \\
$\mathrm{P}$ & $90 \pm 1$ & $91 \pm 1$ \\
$\mathrm{Sb}$ & $426 \pm 6$ & $395 \pm 1$ \\
\hline
\end{tabular}

$\mathrm{TPhP}, \mathrm{Cl}, \mathrm{Br}, \mathrm{P}$, and $\mathrm{Sb}$ in $\mathrm{ABS}$ and $\mathrm{PC}$ resin disks are listed in Table 1 and details of the preparation procedure are described in our previous study. ${ }^{13,14,19}$ The original ABS and PC resin disks (without long-time heating) used in the present study can be seen in Photos 1 and 2, respectively. The diameter and the thickness of the original disk were 30 and $2 \mathrm{~mm}$, respectively; and the original masses of ABS and PC resin disks were $c a$. $1.5 \mathrm{~g}$ and $c a .1 .7 \mathrm{~g}$, respectively. Though the detailed thermal properties were unknown for both plastic disks, the heat resisting temperatures for $\mathrm{ABS}$ and $\mathrm{PC}$ resins were generally known to be $70-100$ and $120-130^{\circ} \mathrm{C}$, respectively. ${ }^{26}$

\section{Instruments}

A drying oven with maximum temperature of $250^{\circ} \mathrm{C}$ was used for long-time heating at $80^{\circ} \mathrm{C}$ in the present study. The heating temperature of $80^{\circ} \mathrm{C}$ is the drying temperature generally used for plastic CRMs for chemical analysis to remove any moisture before analysis. ${ }^{27-29}$ The heating temperature was also close to the temperature of $c a .90^{\circ} \mathrm{C}$ observed at the surface of the plastic disk after $1 \mathrm{~h}$ measurement by a WD-XRF spectrometer in our previous study. ${ }^{22}$ Approximately 1.5 or $1.7 \mathrm{~g}$ of $\mathrm{ABS}$ and $\mathrm{PC}$ resin disks, respectively, were weighed accurately by electric valance (AX 205, Mettler-Toledo International Inc.) and heated in the drying oven at $80^{\circ} \mathrm{C}$ during the heating periods of 0 (without heating), 10, 25, 152, 385 and 722 days. After the long-time heating, the mass of plastic disks and the change in concentrations of elements from FRs were evaluated. In case of mass measurement, the electric valance was used to weigh the mass of both plastic disks. The change in concentrations of elements from FRs was evaluated by an energy dispersive X-ray fluorescence (ED-XRF) spectrometer (Shimadzu XRF Rayny EDX-720, Kyoto, Japan) and the operating condition was listed in Table 2. In the present study, Fourier transform infrared (FTIR) spectrometry was also carried out to identify the chemical forms of ABS and PC disks, and the instrument used was Nicolet 6700 Continu um FTIR (Thermo Fisher Scientific). FTIR with attenuated total reflection (ATR) method was used. The internal reflection element, incidence angle and number of reflections for ATR-FTIR were diamond, 45 degrees and one time, respectively; and the spectral range measured was 650 $4000 \mathrm{~cm}^{-1}$ in the present study. All measurements were carried out after all plastic samples shown in Photos 1 and 2 were ready, that is, after the long-time heating of 722 days.

\section{Results and Discussion}

\section{Plastic disks after long-time heating}

The long-time heating was carried out with respect to ABS and $\mathrm{PC}$ resin disks with FRs and the obtained disks were shown in Photos 1 and 2, respectively. The original colors of the ABS 


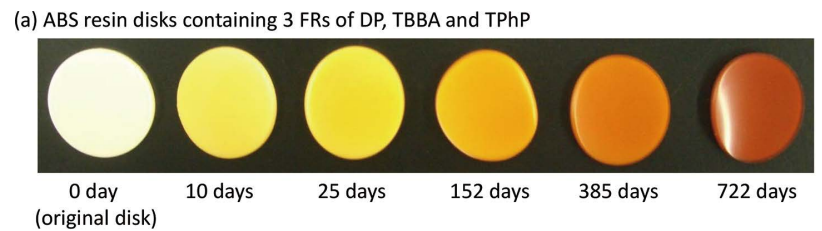

(b) ABS resin disks containing 4 FRs of DP, TBBA, TPhP and $\mathrm{Sb}_{2} \mathrm{O}_{3}$

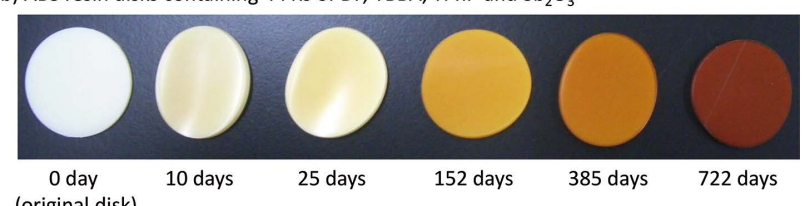

(original disk)
Photo 1 ABS resin disks containing (a) 3 FRs and (b) 4 FRs observed with long-time heating at $80^{\circ} \mathrm{C}$ for 722 days. (a) PC resin disks containing 3 FRs of DP, TBBA and TPhP

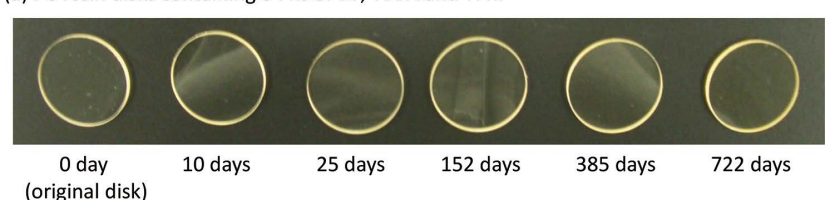

(original disk)

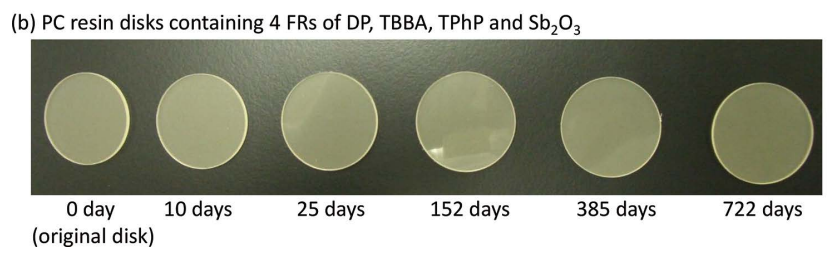

Photo 2 PC resin disks containing (a) 3 FRs and (b) 4 FRs observed with long-time heating at $80^{\circ} \mathrm{C}$ for 722 days.

Table 2 Operating conditions of ED-XRF spectrometer (Rayny EDX-720, Shimadzu)

\begin{tabular}{|c|c|c|c|c|c|}
\hline $\mathrm{X}$-ray & & $\mathrm{Rh} \mathrm{t}$ & arget (air coc & ling) & \\
\hline X-ray irradiated diameter (circle) & & & $10 \mathrm{~mm}$ & & \\
\hline Atmosphere & Atmospheric pressure & Vacuum & Vacuum & Vacuum & Atmospheric pressure \\
\hline Measurand & $\operatorname{Br}\left(\mathrm{K}_{\alpha}\right)$ & $\mathrm{Cl}\left(\mathrm{K}_{\alpha}\right)$ & $\mathrm{P}\left(\mathrm{K}_{\alpha}\right)$ & $\mathrm{Sb}\left(\mathrm{L}_{\alpha}\right)$ & $\mathrm{Sb}\left(\mathrm{K}_{\alpha}\right)$ \\
\hline Filter & $\mathrm{Ag}$ & $\mathrm{Al}$ & $\mathrm{Al}$ & $\mathrm{Al}$ & Non \\
\hline Voltage/kV & 50 & 15 & 15 & 15 & 50 \\
\hline Current $/ \mu \mathrm{A}$ & 800 (auto) & 800 (auto) & 800 (auto) & 800 (auto) & 35 (auto) \\
\hline Integrated energy range $(\mathrm{keV})$ for measurand & $11.6-12.2$ & $2.4-2.8$ & $1.8-2.2$ & $3.4-3.8$ & $25.9-26.7$ \\
\hline Integrated energy range $(\mathrm{keV})$ for Compton scattering & $18.1-19.9$ & $9.5-10.0$ & $9.5-10.0$ & $9.5-10.0$ & $19.9-20.5$ \\
\hline Measurement time/s & 3600 & 9999 & 9999 & 9999 & 3600 \\
\hline Upper limit of detector dead time, $\%$ & & & 40 & & \\
\hline Detector & & $\mathrm{Si}(\mathrm{I}$ & i) semicond & ctor & \\
\hline
\end{tabular}

resin disks (without heating) containing 3 FRs and 4 FRs (without and with $\mathrm{Sb}$, respectively) were milky-white (see Photo 1). On the other hands, the original PC resin disk containing 3 FRs (without $\mathrm{Sb}$ ) was transparent even though the color changed to light-brown when $\mathrm{Sb}$ was added in the PC resin disk (see Photo 2). As can be seen in Photo 1, the shapes and colors of ABS resin disks changed compared to the original one without heating ( 0 day) due to the long-time heating at $80^{\circ} \mathrm{C}$ for more than 10 days even though FRs were contained. The colors observed between ABS resin disks containing 3 FRs and 4 FRs for 10 and 25 days heating were also found to be slightly different, even though others seemed to be similar. Since the heat resisting temperature of ABS resin were generally known to be $70-100^{\circ} \mathrm{C},{ }^{26}$ the change of shape and color were not surprised. The slightly different colors observed between the ABS resin disks containing 3 FRs and 4 FRs for $10-25$ days heating might be attributed to the effect of $\mathrm{Sb}_{2} \mathrm{O}_{3}$ as FR. On the other hand, no obvious changes were observed for both PC resin disks with and without long-time heating. Since the heat resisting temperature of PC resin was generally known to be $120-130^{\circ} \mathrm{C},{ }^{26}$ it was considered that the shape and color of the $\mathrm{PC}$ resin disks did not change under the heating at $80^{\circ} \mathrm{C}$. From these observations, though the PC resin disks seemed to be strong and stable enough with respect to the long-time heating at $80^{\circ} \mathrm{C}$, it could be considered that the ABS resin disks did not have enough strength even though FRs were contained.

Change in concentrations of $\mathrm{Br}, \mathrm{Cl}, \mathrm{P}$ and Sb from FRs in ABS and $P C$ disks

The elements originated from FRs in ABS and PC resin disks such as $\mathrm{Br}, \mathrm{Cl}, \mathrm{P}$ and $\mathrm{Sb}$ were measured by an ED-XRF spectrometer. Figures 1 and 2 show typical ED-XRF spectra obtained by ED-XRF spectrometry with the operating conditions listed in Table 2. The $\mathrm{Cl}\left(\mathrm{K}_{\alpha}\right), \mathrm{Cl}\left(\mathrm{K}_{\alpha}\right)$ and $\mathrm{Sb}\left(\mathrm{L}_{\alpha}\right)$ shown in Fig. 1, which were observed at lower energy, showed small signals even though $\operatorname{Br}\left(\mathrm{K}_{\alpha}\right)$ and $\mathrm{Sb}\left(\mathrm{K}_{\alpha}\right)$ shown in Fig. 2 revealed larger ones. Figure 3 shows the relative changes of $\operatorname{Br}\left(\mathrm{K}_{\alpha}\right)$ signals observed for both ABS and PC resin disks. In the present study, a signal correction method by Compton scattering was carried out to compensate for any possible signal fluctuations due to the different shapes of plastic resin disks, especially for ABS ones observed as shown in Photo 1. It could be seen in Figs. 3(a) and 3(b), the $\operatorname{Br}\left(\mathrm{K}_{\alpha}\right)$ signals without the correction by Compton scattering showed more than $100 \%$ as well as larger variations which were attributed to the changing shapes of the ABS resin disks obtained after the long-time heating. On the other hand, the maximum decreasing rate of $c a$. $5 \%$ was observed for ABS resin disks when the correction method by Compton scattering was carried out. Since the $\operatorname{Br}\left(\mathrm{K}_{\alpha}\right)$ signal was observed at higher energy range of $11.6-12.2 \mathrm{keV}$ as listed in Table 2, the decreasing rate could be related to the concentration changes of $\mathrm{Br}$ on bulk. On the other hand, the decreasing of $\mathrm{Br}\left(\mathrm{K}_{\alpha}\right)$ signals was not observed for PC resin disks by ED-XRF spectrometry in the present study. Since $\mathrm{PC}$ resin showed higher thermal tolerance than that of $\mathrm{ABS},{ }^{26}$ these elements could also be considered to be stable in the PC disk. Figure 4 shows the relative changes of $\mathrm{Cl}\left(\mathrm{K}_{\alpha}\right)$ and $\mathrm{P}\left(\mathrm{K}_{\alpha}\right)$ signals observed for ABS resin disks. No relative changes were observed for $\mathrm{PC}$ resin disks (data not shown). As can be seen in Fig. 4, $\mathrm{Cl}$ and $\mathrm{P}$ in $\mathrm{ABS}$ resin disks with long-time heating 
(a)
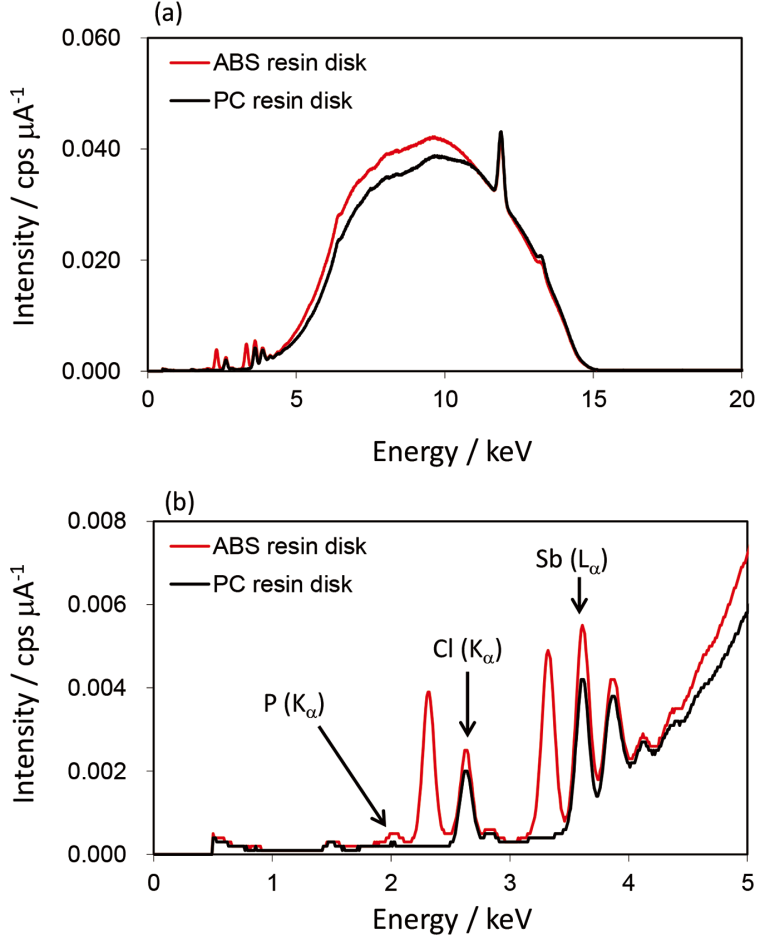

Fig. 1 Typical ED-XRF spectra observed for $\mathrm{Cl}\left(\mathrm{K}_{\alpha}\right), \mathrm{P}\left(\mathrm{K}_{\alpha}\right)$ and $\mathrm{Sb}\left(\mathrm{L}_{\alpha}\right)$ from $\mathrm{ABS}$ and $\mathrm{PC}$ resin disks. The ED-XRF spectra are shown in the range of (a) $0-20$ and (b) $0-5 \mathrm{keV}$. The actual values of voltage, current and detector dead time for ED-XRF spectrometer were $15 \mathrm{kV}, 756 \mu \mathrm{A}$ and $39 \%$, respectively.
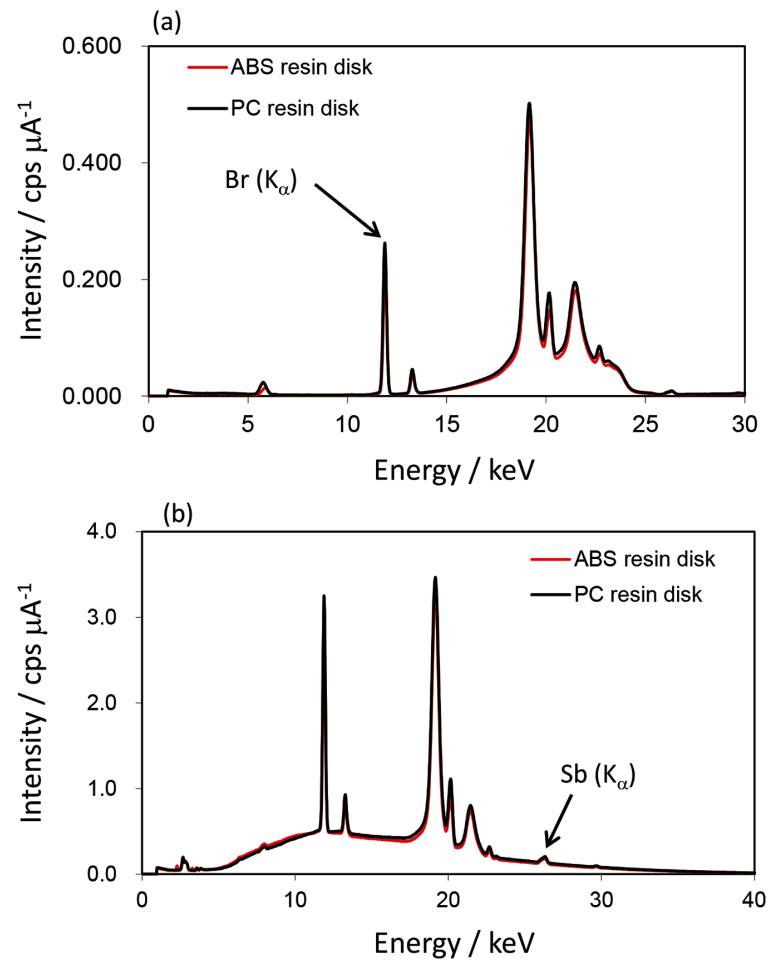

Fig. 2 Typical ED-XRF spectra observed for (a) $\operatorname{Br}\left(\mathrm{K}_{\alpha}\right)$ and (b) $\mathrm{Sb}\left(\mathrm{K}_{\alpha}\right)$ from $\mathrm{ABS}$ and $\mathrm{PC}$ resin disks. The actual values of voltage, current and detector dead time for ED-XRF spectrometer were (a) $50 \mathrm{kV}, 350 \mu \mathrm{A}$ and $39 \%$, and (b) $50 \mathrm{kV}, 36 \mu \mathrm{A}$ and $40 \%$, respectively.
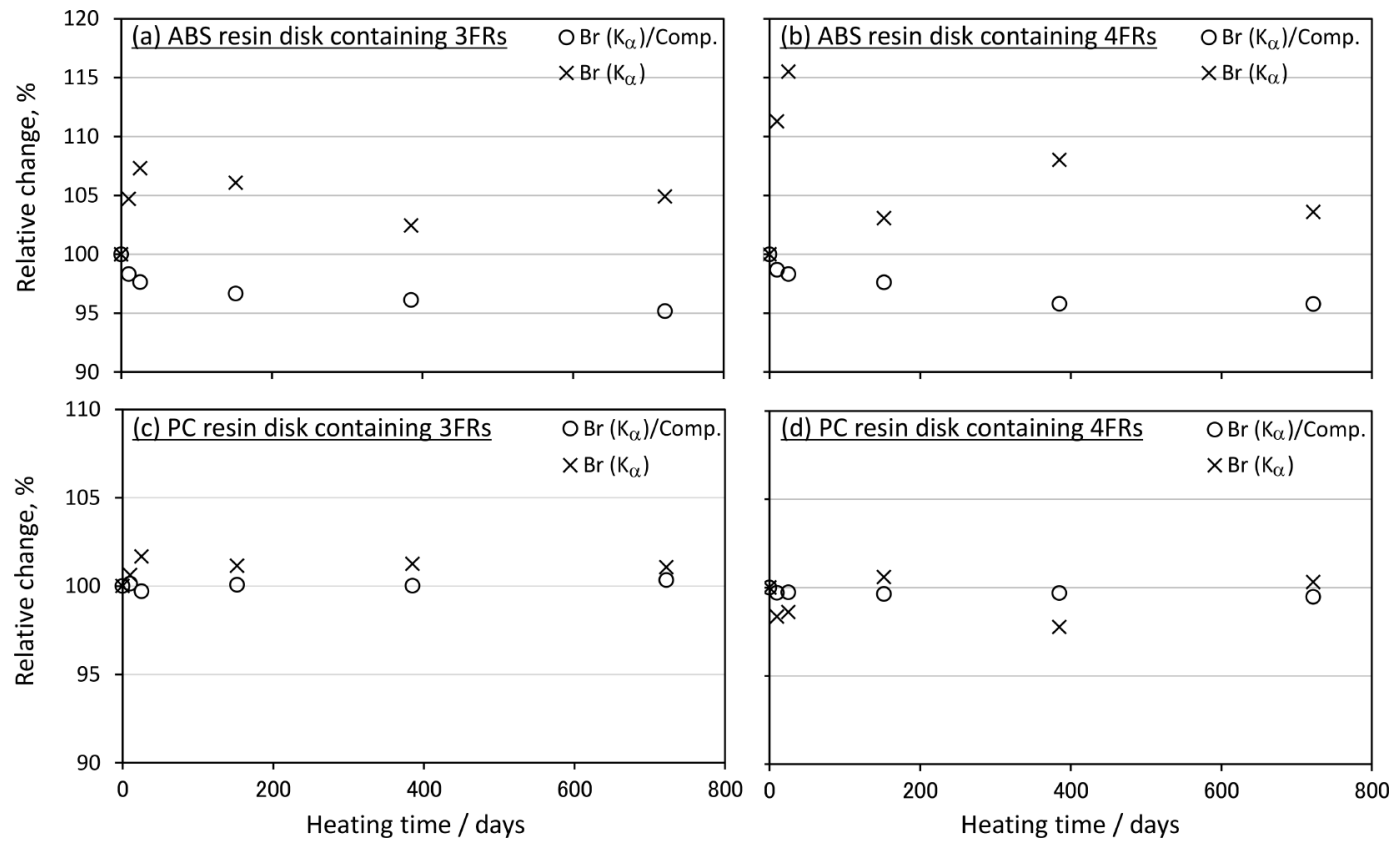

Fig. 3 Relative changes of $\operatorname{Br}\left(\mathrm{K}_{\alpha}\right)$ originated from FRs of TBBPA in ABS and PC resin disks containing 3 FRs and 4 FRs. (a) and (b) or (c) and (d) show the changes for ABS or PC resin disks containing 3 FRs and 4 FRs, respectively. The symbols of $\bigcirc$ and $\times$ show the data with and without corrections by Compton scattering, respectively.

decreased to 20 - $30 \%$ compared to the one without heating. It was also found that the decreasing rate of these elements in ABS resin disk containing 4 FRs (including $\mathrm{Sb}_{2} \mathrm{O}_{3}$ ) under the heating within $10-25$ days was $10-20 \%$ which was smaller than the one containing 3 FRs (without $\mathrm{Sb}_{2} \mathrm{O}_{3}$ ). From these results, it was considered that the ABS disk containing 4 FRs 

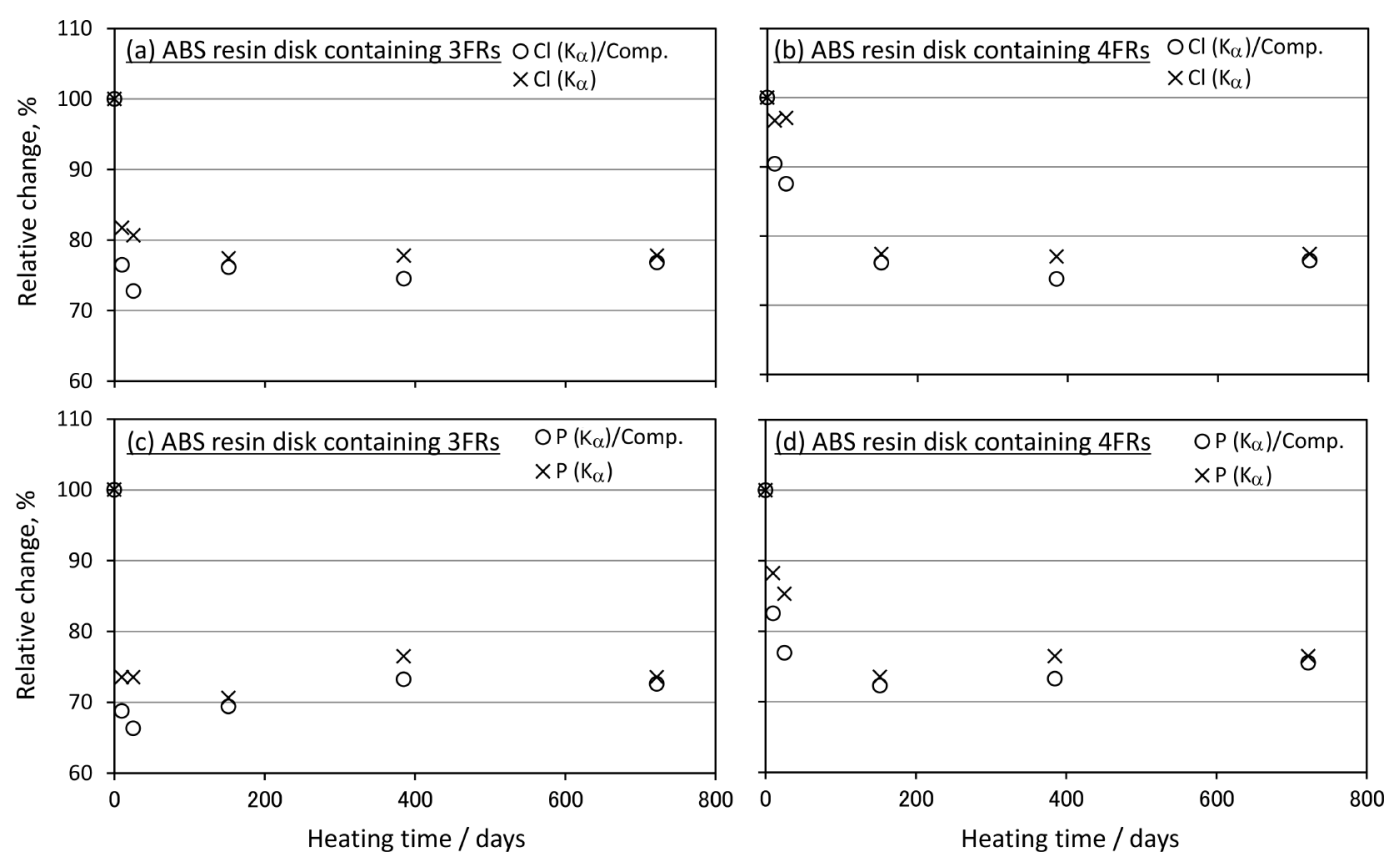

Fig. 4 Relative changes of $\mathrm{Cl}\left(\mathrm{K}_{\alpha}\right)$ and $\mathrm{P}\left(\mathrm{K}_{\alpha}\right)$ originated from FRs of DP and TPhP, respectively, in ABS resin disks containing 3 FRs and 4 FRs. (a) and (b) or (c) and (d) show the changes for $\mathrm{Cl}$ or $\mathrm{P}$ in ABS resin disks containing 3 FRs and 4 FRs, respectively. The symbols of $\bigcirc$ and $\times$ show the data with and without corrections by Compton scattering, respectively.

seemed to show enhanced thermal tolerance compared to the one containing 3 FRs even though the effect was not enough for long-time heating for more than 25 days. Figure 5 shows the relative changes of $\mathrm{Sb}\left(\mathrm{L}_{\alpha}\right)$ and $\mathrm{Sb}\left(\mathrm{K}_{\alpha}\right)$ signals observed for ABS resin disks. It was found that the maximum decreasing rates of $c a .5$ and $c a .25 \%$ were observed for $\mathrm{Sb}\left(\mathrm{K}_{\alpha}\right)$ and $\mathrm{Sb}\left(\mathrm{L}_{\alpha}\right)$ signals, respectively. Since the $\mathrm{Sb}\left(\mathrm{K}_{\alpha}\right)$ signal was observed at higher energy range of $25.9-26.7 \mathrm{keV}$ as listed in Table 2, the relative changes could be related to the concentration changes of $\mathrm{Sb}$ on bulk. On the other hand, it was considered that $\mathrm{Sb}\left(\mathrm{L}_{\alpha}\right)$ signal reflected $\mathrm{Sb}$ from surface of the disk since the signal was observed at lower energy range of $3.4-3.8 \mathrm{keV}$. From this point of view, the relative changes of $\mathrm{Cl}$ and $\mathrm{P}$ shown in Fig. 4 were also considered from the surface of the disk since these signals were observed at lower energy ranges of $2.4-2.8$ and $1.8-2.2 \mathrm{keV}$, respectively. The analytical depths for the measurements of $\mathrm{Cl}, \mathrm{P}$ and $\mathrm{Sb}\left(\mathrm{K}_{\alpha}\right)$ could be $0.1-0.4 \mathrm{~mm}$ from the surface of ABS disk. ${ }^{30,31}$ From these results, decreasing rate of $\mathrm{Cl}, \mathrm{P}$ and $\mathrm{Sb}$ including $\mathrm{Br}$ could be considered to be maximum ca. $5 \%$ for the ABS resin disk.

\section{Changing mass and chemical form of $A B S$ and $P C$ resin disks by} long-time heating

The changing mass for $\mathrm{ABS}$ and $\mathrm{PC}$ resin disks was investigated as shown in Figs. 6(a) and 6(b), respectively; since their masses could be changing due to the loss of water from disk surface or the changing their chemical forms by the longtime heating. As can be seen in Fig. 6(a), the masses of ABS resin disks containing 3 FRs and 4 FRs increased up to $c a$. $4 \%$ during the long-time heating for 722 days and the changes of their masses were similar to each other except for the ones observed for $10-25$ days of heating. The observed phenomena could fit the changes of the colors between ABS resin disks containing 3 FRs and 4 FRs observed for 10-25 days (see Photo 1). From these results, the concentrations of FRs and

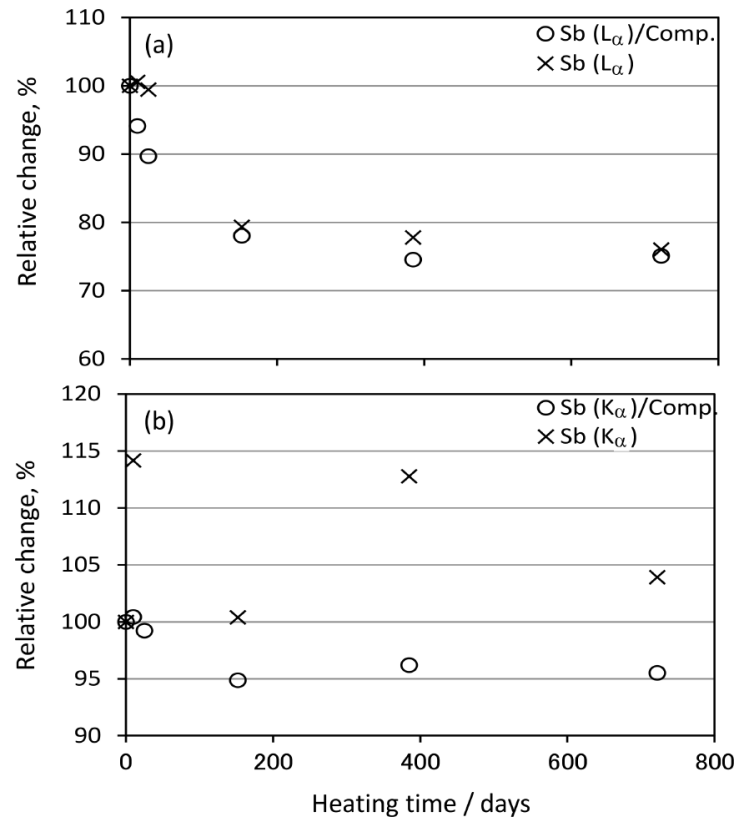

Fig. 5 Relative changes of (a) $\mathrm{Sb}\left(\mathrm{L}_{\alpha}\right)$ and (b) $\mathrm{Sb}\left(\mathrm{K}_{\alpha}\right)$ originated from FRs of $\mathrm{Sb}_{2} \mathrm{O}_{3}$ in ABS resin disks containing 4 FRs. The symbols of $\bigcirc$ and $\times$ show the data with and without corrections by Compton scattering, respectively.

related elements should be changed since the masses of ABS resin disks increased. If the FRs and related elements are not lost, their concentrations become $c a$. $4 \%$ lower than those of original ABS resin disks during the long-time heating for 722 days. As mentioned in previous section, the decreasing rates of $\mathrm{Cl}, \mathrm{P}$ and $\mathrm{Sb}$ including $\mathrm{Br}$ could be considered to be maximum 
ca. $5 \%$ and the rates were similar to the increasing rate of mass (ca. 4\%) for the ABS resin disk, even though both rates were not completely matched. On the other hand, PC resin disks showed almost no mass changes from original one to the ones with long-time heating for 722 days as shown in Fig. 6(b). The changes of masses between the PC resin disks containing 3 FRs and 4 FRs were also similar. Since the PC resin disks showed no changes of colors and masses, it could be considered that the

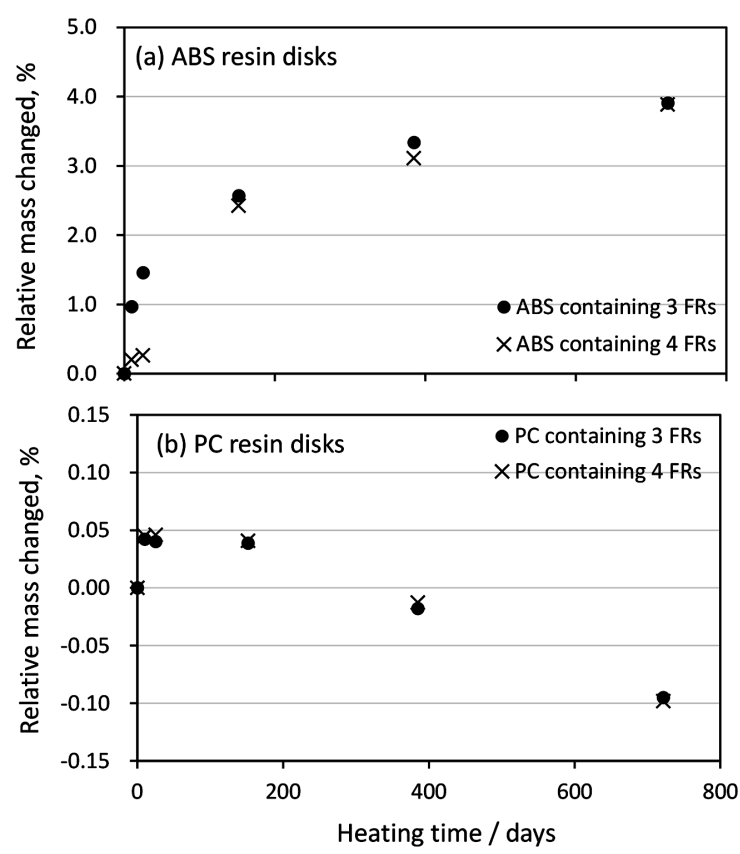

Fig. 6 Changes in the masses of (a) ABS and (b) PC resin disks as a function of the heating time. The symbols of $\bullet$ and $\times$ show the data for plastic disks containing 3 FRs and 4 FRs, respectively. disk seemed to be strong and stable enough with respect to the long-time heating at $80^{\circ} \mathrm{C}$ for 722 days, which might be attributed to the thermal tolerance of PC resin. ${ }^{26}$ In order to examine the changing mass of ABS resin disk during the longtime heating, FTIR measurement was carried out to evaluate the chemical form. Figure 7 shows ATR-FTIR spectra observed for both ABS and PC resin disks. The negative spectra with some noises observed were attributed to the effects of $\mathrm{CO}_{2}(2300-$ $2400 \mathrm{~cm}^{-1}$ ) and $\mathrm{H}_{2} \mathrm{O}$ ( ca. 1600 and $3600-3800 \mathrm{~cm}^{-1}$ ) in air from blank measurement. It could be seen from Figs. 7(a) and 7(b), the differences during long-time heating were found for ABS resin disks especially in 910, $1000-1250,1600-1700$ and $2800-2900 \mathrm{~cm}^{-1}$ which corresponded to $\mathrm{C}=\mathrm{C}$ double bound, ether $(\mathrm{C}-\mathrm{O}-\mathrm{C})$, ketone $(\mathrm{C}=\mathrm{O})$ and methylene $\left(=\mathrm{CH}_{2}\right)$ groups, respectively. ${ }^{32}$ It could be seen that the $\mathrm{C}=\mathrm{C}$ double bond as well as methylene group decreased and both the ether and ketone groups increased in ABS resin disk. Since the $\mathrm{C}=\mathrm{C}$ double bond could be found in butadiene group in ABS, the double bond was considered to be oxidized by the oxygen from ambient air and changed to ether and ketone groups during long-time heating which resulted in the increasing mass of ABS resin disk. Similar phenomenon was observed in our previous study. ${ }^{33}$ On the contrary, no differences were found for PC resin disks as shown in Figs. 7(c) and 7(d). Since the PC resin does not have $\mathrm{C}=\mathrm{C}$ double bond like a butadiene group in $\mathrm{ABS}$, the oxidation did not occur which sustained its chemical form stable without mass changing. From these results, though the PC resin disk seemed to be strong and stable enough with respect to the long-time heating at $80^{\circ} \mathrm{C}$, the $\mathrm{ABS}$ resin disk was considered to be oxidized which resulted in increasing its mass as well as decreasing concentrations of FRs contained. Though both increasing and decreasing rates were not completely matched, most of the changes in concentrations of elements from FRs could be due to the changes in mass of the ABS resin disk observed during the long-time heating. Therefore, it could be also considered that the most of the elements from FRs in ABS and $\mathrm{PC}$ resin disks was not lost even if these plastics were
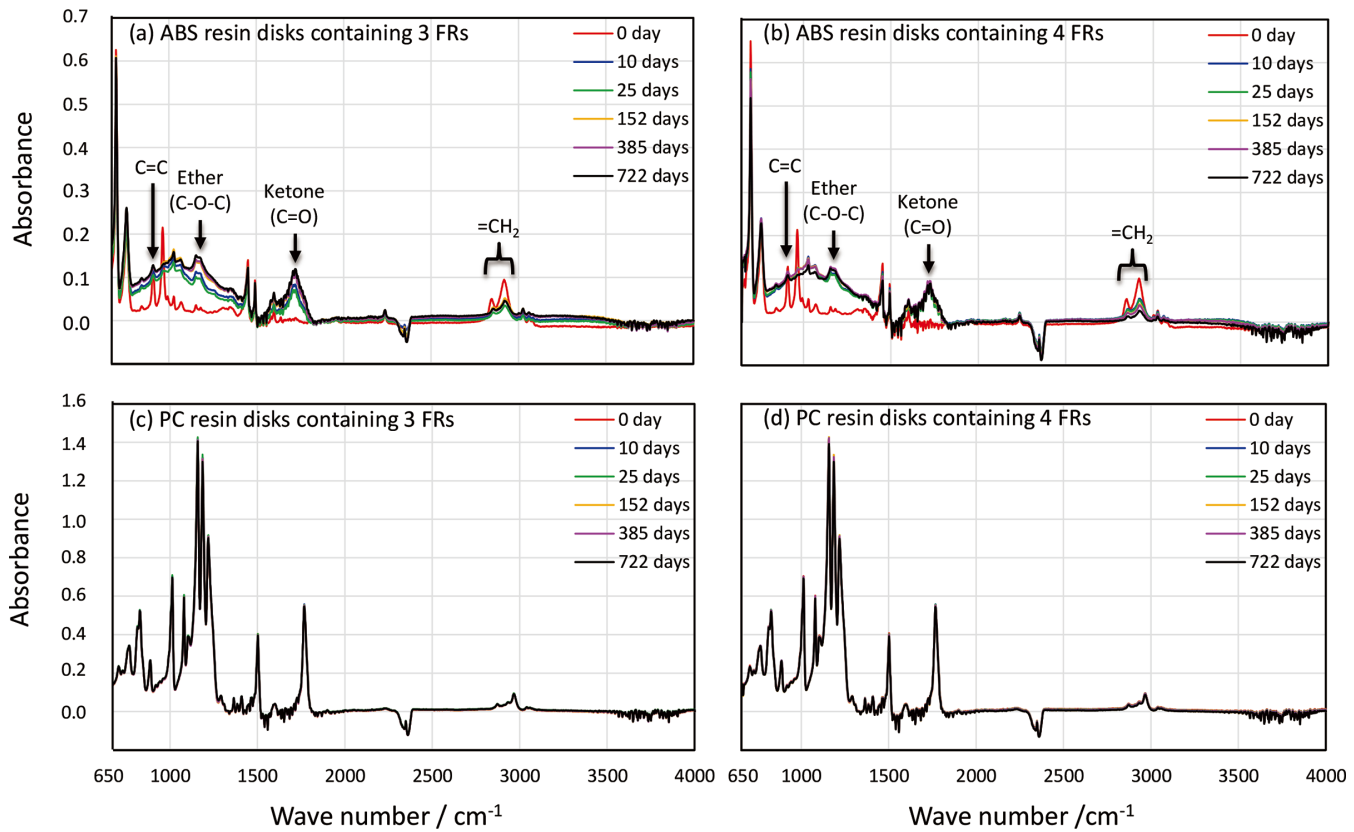

Fig. 7 ATR-FTIR spectra observed for ABS and PC resin disks containing 3 FRs or 4 FRs. (a) and (b) or (c) and (d) show the spectra for ABS or PC resin disks containing 3 FRs and 4 FRs, respectively. 
discarded at harder environment such as higher temperature examined in the present study.

\section{Conclusions}

The effect of long-time heating for elements from FRs such as DP, TBBPA, TPhP and $\mathrm{Sb}_{2} \mathrm{O}_{3}$ in both ABS and PC resin disks was examined in the present study. The decreases in concentrations of $c a .5 \%$ for $\mathrm{Br}, \mathrm{Cl}, \mathrm{P}$ and $\mathrm{Sb}$ originated from FRs were found for ABS disk; however, no changes were observed for PC disk. The increases in mass of the ABS resin disk was found to be up to $c a$. $4 \%$ during the long-time heating, even though the $\mathrm{PC}$ resin disk did not reveal any large changing. The increases for both ether $(\mathrm{C}-\mathrm{O}-\mathrm{C})$ and ketone $(\mathrm{C}=\mathrm{O})$ groups and the decreases of $\mathrm{C}=\mathrm{C}$ double bond as well as methylene group $\left(=\mathrm{CH}_{2}\right)$ for $\mathrm{ABS}$ resin disk were found and it was considered to result in an increase of $\mathrm{ca}$. $4 \%$ mass by oxidation. Though both decreasing and increasing rates were not completely matched, most of the changes in concentrations of elements could be due to the changes in mass of the ABS resin disk observed during the long-time heating. Though the longtime heating could be considered to be harder environment than that of usual dump site for discarding electric and electronic equipment, it was concluded that most of elements from DP, TBBPA, TPhP and $\mathrm{Sb}_{2} \mathrm{O}_{3}$ contained as FRs in the ABS and PC resin plastics examined in the present study were not lost, even though the color, shape, mass and chemical form of ABS resin disk were changed.

\section{Acknowledgements}

This work was supported by the Environment Research and Technology Development Fund (3K133009) of the Ministry of the Environment, Japan.

\section{References}

1. The European Parliament and the Council of the European Union. Directive 2002/95/EC of the European parliament and of the council of 27 January 2003, on the restriction of the use of certain hazardous substances in electrical and electronic equipment, Off. J. Eur. Union, 2003, 37, 19.

2. The European Parliament and the Council of the European Union. Directive 2011/65/EC of the European parliament and of the council of 8 June 2011, on the restriction of the use of certain hazardous substances in electrical and electronic equipment (recast), Off. J. Eur. Union, 2011, 174, 88.

3. National Institute for Environmental Studies: Survey on Macro Flow of Plastic Materials, 2003.

4. S. Kemmlein, O. Hahn, and O. Jann, Atmos. Environ., 2003, 37, 5485.

5. Å. Bergman, A. Rydén, R. J. Law, J. Boer, A. Covaci, M. Alaee, L. Birnbaum, M. Petreas, M. Rose, S. Sakai, N. Eede, and I. Veen, Environ. Int., 2012, 49, 57.

6. I. Veen and J. Boer, Chemosphere, 2012, 88, 1119.

7. P. Zhang, L. Song, H. Lu, J. Wang, and Y. Hu, Energy
Convers. Manage., 2010, 51, 2733.

8. I. C. Nnorom and O. Osibanjo, Resour. Conserv. Recycl., 2008, 52, 1362.

9. Y. X. Zhao, X. F. Qin, Y. Li, P. Y. Liu, M. Tian, S. S. Yan, Z. F. Qin, X. B. Xu, and Y. J. Yang, Chemosphere, 2009, 76, 1470 .

10. H. Matsukami, N. M. Tue, G. Suzuki, M. Someya, L. H. Tuyen, P. H. Viet, S. Takahashi, S. Tanabe, and H. Takigami, Sci. Total Environ., 2015, 514, 492.

11. N. Kajiwara, Y. Noma, and H. Takigami, Environ. Sci. Technol., 2008, 42, 4404.

12. K. M. Unice, J. L. Bare, M. L. Kreider, and J. M. Panko, Sci. Total Environ., 2015, 533, 476.

13. N. Hanari, M. Ohata, N. Itoh, and T. Otake, Organohalogen Compd., 2014, 76, 49.

14. N. Hanari, T. Otake, N. Itoh, A. Wada, and M. Ohata, Environ. Monit. Assess., 2017, 189, 92.

15. ISO Guide 98-3: Uncertainty of Measurement-Part 3: Guide to the Expression of Uncertainty in Measurement (GUM:1995), 2008.

16. ISO 4892: Plastics-Methods of Exposure to Laboratory Light Sources-Part 2: Xenon-arc Lamps, 2006.

17. T. Otake, N. Itoh, M. Ohata, and N. Hanari, Organohalogen Compd., 2014, 76, 5.

18. T. Otake, N. Itoh, M. Ohata, and N. Hanari, Anal. Lett., 2015, 48, 2319.

19. N. Hanari, T. Otake, N. Itoh, A. Wada and M. Ohata, Kankyo Kagaku, 2016, 26, 61.

20. M. Ohata, T. Kidokoro, M. Kurahashi, and A. Hioki, Bunseki Kagaku, 2010, 59, 903.

21. M. Ohata, T. Kidokoro, and A. Hioki, Anal. Sci., 2012, 28, 1105.

22. M. Ohata and T. Kidokoro, Anal. Sci., 2015, 31, 855.

23. M. Ohata, Anal. Sci., 2016, 32, 1003.

24. IEC 62321 Electrotechnical products-Determination of levels of six regulated substances (lead, mercury, cadmium, hexavalent chromium, polybrominated biphenyls, polybrominated diphenyl ethers), ed. 1.0; International Electrotechnical Commission: Geneva, Switzerland, 2008.

25. K. Nakano, T. Nakamura, I. Nakai, A. Kawase, M. Imai, M. Hasegawa, Y. Ishibashi, I. Inamoto, K. Sudou, M. Kozaki, A. Tsuruta, A. Ono, K. Kakita, and M. Sakata, Anal. Sci., 2006, 22, 1265.

26. http://www.jpif.gr.jp/2hello/conts/youto_c.htm (accessed on Dec. 16, 2017).

27. M. Ohata and A. Hioki, Anal. Sci., 2013, 29, 239.

28. M. Ohata and T. Miura, Anal. Chim. Acta, 2014, 837, 23.

29. A. Wada, T. Miura, M. Ohata, and A. Hioki, Bunseki Kagaku, 2015, 64, 543.

30. M. Kurahashi, J. Mizutani, and A. Hioki, Anal. Sci., 2005, 21, 827.

31. M. Kurahashi, T. Kidokoro, M. Ohata, S. Matsuyama, S. Kinugasa, and A. Hioki, Advances in X-ray Chemical Analysis, Japan, 2009, 40, 203.

32. T. Aoki, E. Satoh, M. Hayashi, M. Uno, and T. Takagi, J. Japan Society of Waste Management Experts, 2004, 15, 191.

33. M. Ohata and A. Hioki, Ind. Eng. Chem. Res., 2016, 55, 5618. 